\title{
Evaluation of parental knowledge after establishing CAH clubs in Vietnam \& Indonesia
}

\author{
Irene Mitchelhill ${ }^{1 *}$, Kate Armstrong ${ }^{2}$, Maria Craig ${ }^{3}$, Vu Chi Dung ${ }^{4}$, Bui Phuong Thao ${ }^{4}$, Nguyen Ngoc Khanh ${ }^{4}$, \\ Thi Bich Ngoc ${ }^{4}$, Thuy Thi Diem Hoang 5,6 , Huynh Quynh, Dong Trieu Phuong Tran ${ }^{5}$, Pham Ngoc Trach 6 , \\ Huynh Thoai Loan ${ }^{6}$, Nguyen Phuong Khanh", Tran Thi Bich Huyen ${ }^{7}$, Aman Pulungan $^{8}$, Frida Soesanti ${ }^{8}$
}

From 8th APPES Biennial Scientific Meeting

Darwin, Australia. 29 October - 1 November 2014

The incidence of Congenital Adrenal Hyperplasia (CAH) in some Asian countries is far higher than in Australia, (eg 1:6000 as per the Filipino Newborn Screening Program). For many families in low and middle-income countries in Asia resources are limited, affordable and reliable access to essential medicines is problematic, and families living remotely are required to travel long distances for medical care [1]. CAH is associated with significant physical \& psychosocial consequences for affected children \& their families where treatment is suboptimal, so there are important equity implications for the global $\mathrm{CAH}$ and paediatric endocrinology communities to consider.

Health education is an integral component of health care in any setting. "CAHPepTalk" is an educational resource that was developed initially for $\mathrm{CAH}$ families in Australia. This validated educational resource has been produced in DVD format and can be facilitated by one health professional. The program includes a translated validated CAH Knowledge Assessment Questionnaire (CAHKAQ) [2], to enable staff to assess patient knowledge in order to evaluate educational needs.

In collaboration with CLAN (Caring \& Living As Neighbours), an Australian NGO committed to optimal quality of life for all children living with chronic health conditions), translation of "CAHPepTalk" into Vietnamese \& Indonesian was undertaken, \& distributed to $\mathrm{CAH}$ Communities in the Asia-Pacific region, was supported by CLAN.

Knowledge of parents of children with $\mathrm{CAH}$ in Vietnam and Indonesia was assessed prior to families attending education programs run at $\mathrm{CAH}$ Club meetings supported by CLAN, in 3 settings: Hanoi, Ho Chi Minh City \& Jakarta. 260 questionnaires have been completed by parents. The results to be presented will include knowledge, management \& demographics.

Using the CAHKAQ is the first step in the education process in order to improve health outcomes for families in any setting, within Australia, Vietnam or Indonesia.

\section{Authors' details}

'Department of Endocrinology, Sydney Children's Hospital (SCHN), Randwick, NSW, Australia. ${ }^{2}$ CLAN: Caring Living with Neighbours, Eastwood, NSW, Australia. ${ }^{3}$ Department of Endocrinology, Children's Hospital (SCHN) Westmead, Sydney, NSW, Australia. ${ }^{4}$ Department of Endocrinology, National Hospital of Pediatrics, Hanoi, Vietnam. ${ }^{5}$ Department of NephrologyEndocrinology, Children's Hospital 2, Ho Chi Minh City, Vietnam.

${ }^{6}$ Department of Pediatrics, Faculty of Medicine, University of Medicine, Ho Chi Minh City, Vietnam. 'Department of Nephrology-Endocrinology, Children's Hospital 1, Ho Chi Minh City, Vietnam. ${ }^{8}$ Department of Child Health, Faculty of Medicine, University of Indonesia, Jakarta, Indonesia.

Published: 28 April 2015

\section{References}

1. Armstrong K, Henderson C, Hoan N, Warne G: Living with Congenital Adrenal Hyperplasia in Vietnam: A survey of Parents. Journal of Pediatric Endocrinology \& Metabolism 2006, 19:1207-1223.

2. King J, Mitchelhill I, Fisher M: Development of a Congenital Adrenal Hyperplasia Knowledge Assessment Questionnaire (CAHKAQ). Journal of Clinical Nursing 2008, 17(13):1689-1696.

\section{doi:10.1186/1687-9856-2015-S1-P53}

Cite this article as: Mitchelhill et al.: Evaluation of parental knowledge after establishing CAH clubs in Vietnam \& Indonesia. International Journal of Pediatric Endocrinology 2015 2015(Suppl 1):P53. 